\title{
Surgical problems and complex procedures: Issues for operative time in robotic totally endoscopic coronary artery bypass grafting
}

\author{
Dominik Wiedemann, MD, ${ }^{\mathrm{a}}$ Nikolaos Bonaros, MD, PhD, ${ }^{\mathrm{a}}$ Thomas Schachner, MD, ${ }^{\mathrm{a}}$ \\ Felix Weidinger, MD, ${ }^{a}$ Eric J. Lehr, MD, PhD, ${ }^{b}$ Mark Vesely, MD, ${ }^{c}$ and Johannes Bonatti, MD, FECTS ${ }^{b}$
}

\begin{abstract}
Objective: Robotically assisted totally endoscopic coronary artery bypass grafting (TECAB) is a viable option for closed chest coronary surgery, but it requires learning curves and longer operative times. This study evaluated the effect of extended operation times on the outcome of patients undergoing TECAB.
\end{abstract}

\begin{abstract}
Methods: From 2001 to 2009, 325 patients underwent TECAB with the da Vinci telemanipulation system. Correlations between operative times and preoperative, intraoperative, and early postoperative parameters were investigated. Receiver operating characteristic analysis was used to define the threshold of the procedure duration above which intensive care unit stay and ventilation time were prolonged. Demographic data, intraoperative and postoperative parameters, and survival data were compared.
\end{abstract}

Results: Patients with prolonged operative times more often underwent multivessel revascularization $(P<.001)$ and beating-heart TECAB $(P=.023)$. Other preoperative parameters were not associated with longer operative times. Incidences of technical difficulties and conversions $(P<.001)$ were higher among patients with longer operative times. Prolonged intensive care unit stay, mechanical ventilation, hospital stay, and with requirement of blood products were associated with longer operative times. Receiver operating characteristic analysis showed operative times $>445$ minutes and $>478$ minutes to predict prolonged ( $>48$ hours) intensive care unit stay and mechanical ventilation, respectively. Patients with procedures $>478$ minutes had longer hospital stays and higher perioperative morbidity and mortality. Kaplan-Meier analysis revealed decreased survival among patients with operative times $>478$ minutes.

Conclusions: Multivessel revascularization and conversions lead to prolonged operative times in totally endoscopic coronary artery bypass grafting. Longer operative times significantly influence early postoperative and midterm outcomes. (J Thorac Cardiovasc Surg 2012;143:639-47)

\section{Supplemental material is available online.}

During the last decade, totally endoscopic coronary artery bypass grafting (TECAB) has become a feasible treatment option for an increasing number of patients. ${ }^{1-3}$ Robotic technology is the only reproducible method to perform TECAB, working exclusively through thoracic ports. As the procedure and technology have matured, it is possible to successfully complete increasingly complex operations. Recently, Bonaros and colleagues ${ }^{4}$ showed that TECAB

From the University Clinic of Cardiac Surgery, ${ }^{\mathrm{a}}$ Innsbruck Medical University, Innsbruck, Austria; and the Division of Cardiac Surgery, ${ }^{\mathrm{b}}$ Department of Surgery, and Division of Cardiology, ${ }^{\mathrm{c}}$ University of Maryland Medical Center, Baltimore, Md. Disclosures: J.B. received research grants and consulting fees from Intuitive Surgical, Inc, Sunnyvale, Calif.

Received for publication Jan 31, 2011; revisions received April 5, 2011; accepted for publication April 26, 2011; available ahead of print July 1, 2011.

Address for reprints: Dominik Wiedemann, MD, University Clinic of Cardiac Surgery, Innsbruck Medical University, Anichstrasse 35, 6020 Innsbruck, Austria (E-mail: dominik.wiedemann@i-med.ac.at).

$0022-5223 / \$ 36.00$

Copyright (c) 2012 by The American Association for Thoracic Surgery

doi:10.1016/j.jtcvs.2011.04.039 can reduce postoperative pain and accelerate return to a normal lifestyle without increases in perioperative mortality and morbidity.

These days, not only single and double TECAB procedures (with the left and right internal thoracic arteries [ITAs]) but also triple bypass grafting, Y-grafts, and hybrid procedures are feasible at dedicated centers. Nevertheless, the TECAB procedure is rather complex. Therefore, dry laboratory and wet laboratory training models have been established to reduce the learning curves of surgeons being trained in TECAB. Schachner and associates ${ }^{5}$ recently showed that TECAB can be well taught with a stepwise training program involving portions of the procedure performed by trainees. With such an approach, independent performance after training can be within adequate time limits with seemingly acceptable results. Nevertheless, the TECAB procedure is associated with increased operative times relative to a sternotomy approach. Longer operative times in TECAB are associated with longer crossclamp times, longer cardiopulmonary bypass times, and longer single-lung ventilation times. ${ }^{6}$ All these factors could significantly affect postoperative morbidity and mortality among patients undergoing TECAB. In this study, we investigated whether prolonged operative times have an impact 


\section{Abbreviations and Acronyms \\ ITA $=$ internal thoracic artery \\ LAD $=$ left anterior descending \\ $\mathrm{TECAB}=$ totally endoscopic coronary artery \\ bypass grafting}

on the postoperative outcome of patients undergoing TE$\mathrm{CAB}$. We tried to identify preoperative risk factors for prolonged operative times and to define the threshold of operation duration beyond which perioperative and midterm outcome was affected.

\section{MATERIALS AND METHODS}

From 2001 to 2009, a total of 325 patients underwent TECAB at 2 centers (University Clinic of Cardiac Surgery, Innsbruck Medical University, Innsbruck, Austria; and Department of Surgery, Division of Cardiac Surgery, University of Maryland Medical Center, Baltimore, Md). Demographic data are listed in Table 1.

All patients scheduled for a single-vessel or multivessel totally endoscopic approach on the beating or the arrested heart were included in the study. We have previously described the operative technique. ${ }^{7}$ Beatingheart procedures were performed when the anatomy of the target vessels was suitable for a beating-heart approach, and severely calcified target vessels were regarded as contraindication to a beating-heart procedure. In cases of contraindications for the endoballoon (eg, severely calcified femoral vessels), a beating-heart procedure was performed as a secondary strategy. During the initial period of our program, we performed more on-pump arrested-heart procedures for safety reasons.

For preoperative planning, every patient underwent computed tomography of the ascending aorta. Carotid duplex scanning was also done in every case.

A video of the procedure is available online at http://www.orlive.com/ umm/videos/tecab-totally-endoscopic-coronary-artery-bypass and on the Web site of the Minimally Invasive Robotic Association (http://www. miraweb.org/video.htm).

All patients gave informed consent for the procedure. Data were entered into an institutional review board-approved database. Most of the cases performed at the University of Maryland were performed in a hybrid room. The cases performed at Innsbruck Medical University were done in a regular cardiac operating room with the use of an advanced mobile C-arm.

\section{Statistics}

The data of the patients were prospectively collected and retrospectively analyzed with SPSS statistical software (PASW version 18.0 for Macintosh; IBM Corporation, Somers, NY). Categoric variables are shown as number and percentage and continuous variables as median and range. Operative times were correlated with continuous variables by means of the Spearman test. To define cutoff levels from which point on prolonged operative times negatively influence intensive care unit stay and mechanical ventilation time, we used receiver operating characteristic analysis. For comparison of continuous variables with and without prolonged operative times, we used the Mann-Whitney test; for comparison of categoric variables, we used the $\chi^{2}$ test. To compare the operative times of different procedures, we used analysis of variance.

For multivariate analysis of risk factors for prolonged operative times, the significant predictors of univariate analysis were entered into a binary logistic regression model. The $P$ value, the Wald coefficient, and the hazard ratio with the $95 \%$ confidence interval were determined. Survivals were compared with Kaplan-Meier analysis and log-rank testing.

\section{Definitions}

Operative times were defined as times from skin incision to skin closure. This included intraoperative angiography, which was performed as quality control in 235 of 325 patients. Median procedure time for the angiography was 22 minutes (range, 10-110 minutes). This times was included in the overall operative time. Technical difficulties during the operation were defined as technical challenges that led to either prolongation of procedure time for more than 15 minutes or conversion to a larger incision. Conversion was defined as a switch to a larger incision, including thoracotomy or sternotomy, during or immediately after the TECAB procedure. Mechanical ventilation times and intensive care unit stay longer than 48 hours were defined as prolonged.

\section{RESULTS}

Preoperative demographic factors such as body mass index, EuroSCORE, New York Heart Association functional classification, serum creatinine, and ejection fraction did not show any significant correlation with operative times (Table 2). in contrast, operative time was significantly correlated with intraoperative factors such as cardiopulmonary bypass time $(r=0.708, P<.001)$ and aortic occlusion time $(r=0.657, P<.001)$. Postoperative mechanical ventilation time $(r=0.356, P<.001)$, intensive care unit stay $(r=0.197, P<.001)$, hospital stay $(r=0.268, P<.001)$, and transfused packed red blood cell units $(r=0.395, P>$ .001) showed significant correlation with the operative time (Table 2, Figure 1). Analysis of the receiver operating characteristic curves showed that operative times of at least 445 minutes were predictive of prolonged intensive care unit stay ( $>48$ hours).The operative time cutoff level was 478 minutes for prediction of prolonged mechanical ventilation time ( $>48$ hours, Figure 2$)$. According to these results, we divided the patients into 2 groups (operative time $\geq 478$ minutes, $\mathrm{n}=56$, and operative time $<478$ min, $n=269$ ). When comparing the demographic profiles of these groups, we could not find any parameter that was significantly different (Table 1). Comparison of intraoperative and early postoperative data revealed significantly more beating-heart procedures $(71 \%$ vs $14 \%, P=.023)$ and multivessel procedures $(69 \%$ vs $17 \%, P<.001)$ in the group with prolonged operative times. The use of bilateral ITA grafts $(53 \%$ vs $6 \%, P<.001)$ was also more frequent. We found intraoperative technical difficulties (anastomotic problems, $20 \%$ vs $6 \%, P<.001$, left ITA injuries, $16 \%$ vs $4 \%, P=.003$, and epimyocardial lesions, $16 \%$ vs $6 \%$, $P=.047)$ and conversions to larger thoracic incisions $(41 \%$ vs $8 \%, P<.001)$ significantly more often when operative times were prolonged. Eight of the 46 conversions of the series were performed because of an unsatisfying result of the intraoperative angiographic evaluation of the quality of the anastomosis. When comparing the different TECAB procedures, we could confirm as expected that the operative times of more complex procedures were 
TABLE 1. Demographic data

\begin{tabular}{|c|c|c|c|c|}
\hline & $\begin{array}{l}\text { All patients } \\
(\mathbf{n}=\mathbf{3 2 5})\end{array}$ & $\begin{array}{c}\text { Operative time } \\
\geq 478 \mathrm{~min}(n=56)\end{array}$ & $\begin{array}{c}\text { Operative time } \\
<478 \min (n=269)\end{array}$ & $P$ value \\
\hline Age (y, median and range) & $62(31-90)$ & $62(43-82)$ & $59(31-90)$ & .2 \\
\hline Male (no.) & $240(74 \%)$ & $41(80 \%)$ & $193(73 \%)$ & .649 \\
\hline Female (no.) & $84(26 \%)$ & $10(20 \%)$ & $70(27 \%)$ & .649 \\
\hline EuroSCORE (median and range) & $2(0-8)$ & $2(0-8)$ & $2(0-8)$ & .14 \\
\hline Body mass index $\left(\mathrm{kg} / \mathrm{m}^{2}\right.$, median and range $)$ & $27(14-47)$ & $28(14-46)$ & $27(19-47)$ & .88 \\
\hline History of smoking (no.) & $96(30 \%)$ & $15(30 \%)$ & $81(31 \%)$ & .399 \\
\hline Diabetes mellitus (no.) & $61(19 \%)$ & $14(28 \%)$ & $47(18 \%)$ & .534 \\
\hline Hypercholesterolemia (no.) & $203(63 \%)$ & $33(65 \%)$ & $170(64 \%)$ & .61 \\
\hline Arterial hypertension (no.) & $243(75 \%)$ & $40(71 \%)$ & $203(77 \%)$ & .233 \\
\hline Previous percutaneous coronary intervention (no.) & $77(24 \%)$ & $17(34 \%)$ & $60(23 \%)$ & .362 \\
\hline History of myocardial infarction (no.) & $88(27 \%)$ & $16(31 \%)$ & $69(26 \%)$ & .380 \\
\hline Preoperative unstable angina (no.) & $118(36 \%)$ & $2(4 \%)$ & $24(9 \%)$ & .387 \\
\hline History of thoracic surgery (no.) & $1(0.3 \%)$ & 0 & $1(0.4 \%)$ & 641 \\
\hline Preoperative ejection fraction ( $\%$, median and range) & $60 \%(20 \%-88 \%)$ & $60 \%(35 \%-77 \%)$ & $60 \%(20 \%-88 \%)$ & .4 \\
\hline Peripheral vascular disease (no.) & $8(2.5 \%)$ & $1(2 \%)$ & $7(3 \%)$ & .727 \\
\hline Preoperative serum creatinine ( $\mathrm{md} / \mathrm{dL}$, median and range) & $0.98(0.48-8.70)$ & $0.98(0.66-2.1)$ & $0.97(0.48-8.7)$ & .34 \\
\hline History of transient ischemic attack (no.) & $11(3 \%)$ & $3(6 \%)$ & $8(3 \%)$ & .398 \\
\hline History of stroke (no.) & $3(1 \%)$ & $1(2 \%)$ & $2(0.8 \%)$ & .469 \\
\hline Systolic pulmonary arterial pressure $>60 \mathrm{~mm} \mathrm{Hg}$ (no.) & $1(0.3 \%)$ & 0 & $1(0.4 \%)$ & 658 \\
\hline Chronic obstructive pulmonary disease (all comers, no.) & $32(10 \%)$ & $8(16 \%)$ & $24(9 \%)$ & .261 \\
\hline Preoperative intra-aortic counterpulsation pump (no.) & $5(2 \%)$ & $1(2 \%)$ & $4(2 \%)$ & .556 \\
\hline
\end{tabular}

significantly longer than those of simpler operations. There were no triple-vessel bypasses in this series. Overall, there were 81 double-vessel TECABs, and among those 38 cases were left ITA to left anterior descending (LAD) with diagonal branch as jump graft. The other 43 cases were double-vessel bypasses with bilateral ITA grafts. In these cases, 1 target vessel was the LAD and the other was either an obtuse marginal branch of the circumflex artery or the right coronary artery.

Arrested-heart single left ITA to LAD cases lasted only 295 minutes (range, 175-690 minutes), whereas beatingheart single left ITA to LAD cases needed 347 minutes (range, 195-630 minutes). Whereas performing left ITA to LAD with diagonal branch as jump graft, the arrested-

TABLE 2. Correlations with operative time

\begin{tabular}{lcr}
\hline & \multicolumn{2}{c}{ Operative time } \\
\cline { 2 - 3 } & $\boldsymbol{r}$ value & $\boldsymbol{P}$ value \\
\hline EuroSCORE & 0.065 & .248 \\
Body mass index & -0.001 & .986 \\
Creatinine & 0.036 & .541 \\
Ejection fraction & -0.07 & .913 \\
New York Heart Association & -0.103 & .154 \\
$\quad$ functional class & & \\
Intensive care unit stay & 0.197 & $<.001$ \\
Ventilation time & 0.356 & $<.001$ \\
Hospital stay & 0.268 & $<.001$ \\
Packed red blood cell & 0.395 & $<.001$ \\
$\quad$ transfusion & & \\
\hline
\end{tabular}

heart cases lasted 355 minutes (range, 248-710 minutes), the same procedure performed on the beating heart lasted 465 minutes (range, 360-667 minutes). More complex multivessel cases with bilateral ITA use lasted 502 minutes (range, 330-724 minutes) on the arrested heart and 504 minutes (range, 360-667 minutes) on the beating heart $(P<.001)$ The requirement of packed red blood cell units (3 units; range, 0-21 units; vs 1 unit; range, 0-12 units; $P<.001)$ was significantly higher when operative times exceeded 478 minutes. Requirement of intra-aortic counterpulsation pumps was significantly more prevalent among patients with prolonged operative times $(8 \%$ vs $0.4 \%$, $P<.001)$. Postoperative complications including pneumonia $(14 \%$ vs $1 \%, P<.001)$, renal failure requiring hemofiltration $(6 \%$ vs $0 \%, P<.001)$, sepsis $(2 \%$ vs $0 \%, P=.03)$, and in-hospital mortality ( $4 \%$ vs $0 \%, P=.002)$, were significantly more frequent in the group with prolonged operative times.

Multivariate analysis showed that more complex procedures (bilateral ITA cases, $P<.001$; hazard ratio, 9.674; 95\% confidence interval, 2.885-32.445; Wald, 13.512; and conversions, $P<.001$; hazard ratio, $8.897 ; 95 \%$ confidence interval, 3.146-25.160; Wald, 16.980) were independent predictors for prolonged operative times (Table 3).

Survivals were $99 \%, 98 \%$, and $98 \%$, respectively, in the group without prolonged operative times at 12, 24, and 36 months after the operation. In the group with prolonged operative times, survivals were $92 \%, 92 \%$, and $92 \%$, respectively, at 12,24 , and 36 months after surgery $(P=.02$; 

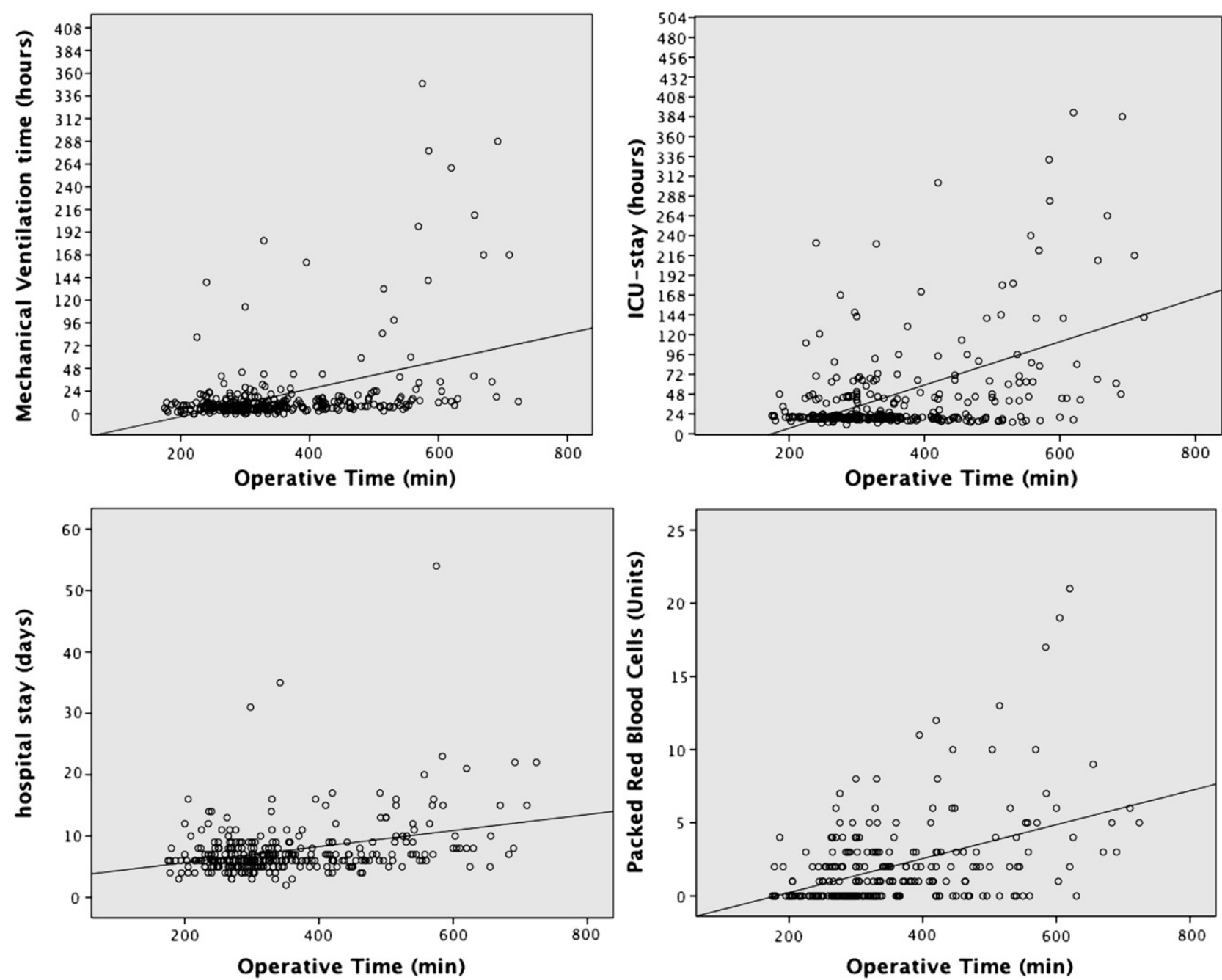

FIGURE 1. Scatter plots of most significant correlations. Operative time significantly correlates with mechanical ventilation time, intensive care unit (ICU) stay, hospital stay, and transfused packed red blood cell units.

Figure 3). Overall, 6 patients in the whole series of $325 \mathrm{TE}$ CABs died. In the group with operative times shorter than 478 minutes 1 patient died of prostate cancer 24 months after the procedure. The other 2 deaths in that group were cardiac related: 1 sudden cardiac death at 4 postoperative months and 1 myocardial infarction 23 months after surgery. In the group with prolonged operative times (longer than 478 minutes), 2 in-hospital deaths occurred: 1 was of intracerebral bleeding and the other was a sudden cardiac death. In the long-term follow-up, another patient in this group died of myocardial infarction.

We identified 2 major factors influencing the operative time in patients undergoing TECAB, namely intraoperative technical problems, especially when leading to conversions, and more complex multivessel revascularizations. Our results indicate that intraoperative technical challenges, observed in $37 \%$ of our patients, not only prolong operative times but are significant determinants of postoperative outcome. We defined surgical problems as listed in Table 4: ITA injury, 9 (6\%); anastomotic problems, $29(9 \%)$; problems with remote access, $52(16 \%)$; port problems, $30(9 \%)$; and epimyocardial lesions, $26(9 \%)$. We divided the patients into 2 groups, those without any surgical problems $(n=205,63 \%)$ and those with surgical problems $(n=120,37 \%)$. If 1 or more of the listed events occurred, a patient was added to the group with surgical problems (Table E1). We found that patients with surgical problems had significantly longer operative time (418 minutes; range, 245-724 minutes; vs 293 minutes; range, 175-656 minutes; $P<.001$ ), as well as longer cardiopulmonary bypass and aortic crossclamp times. There was no significant difference between those with and without surgical problems in the number of multivessel TECABs $(36,29 \%$, vs $45,23 \%$, $P=.18)$ or in the number of bilateral ITA cases (19, $16 \%$, vs $22,12 \%, P=.3$ ), but there were significantly more beating-heart cases in the group with surgical 

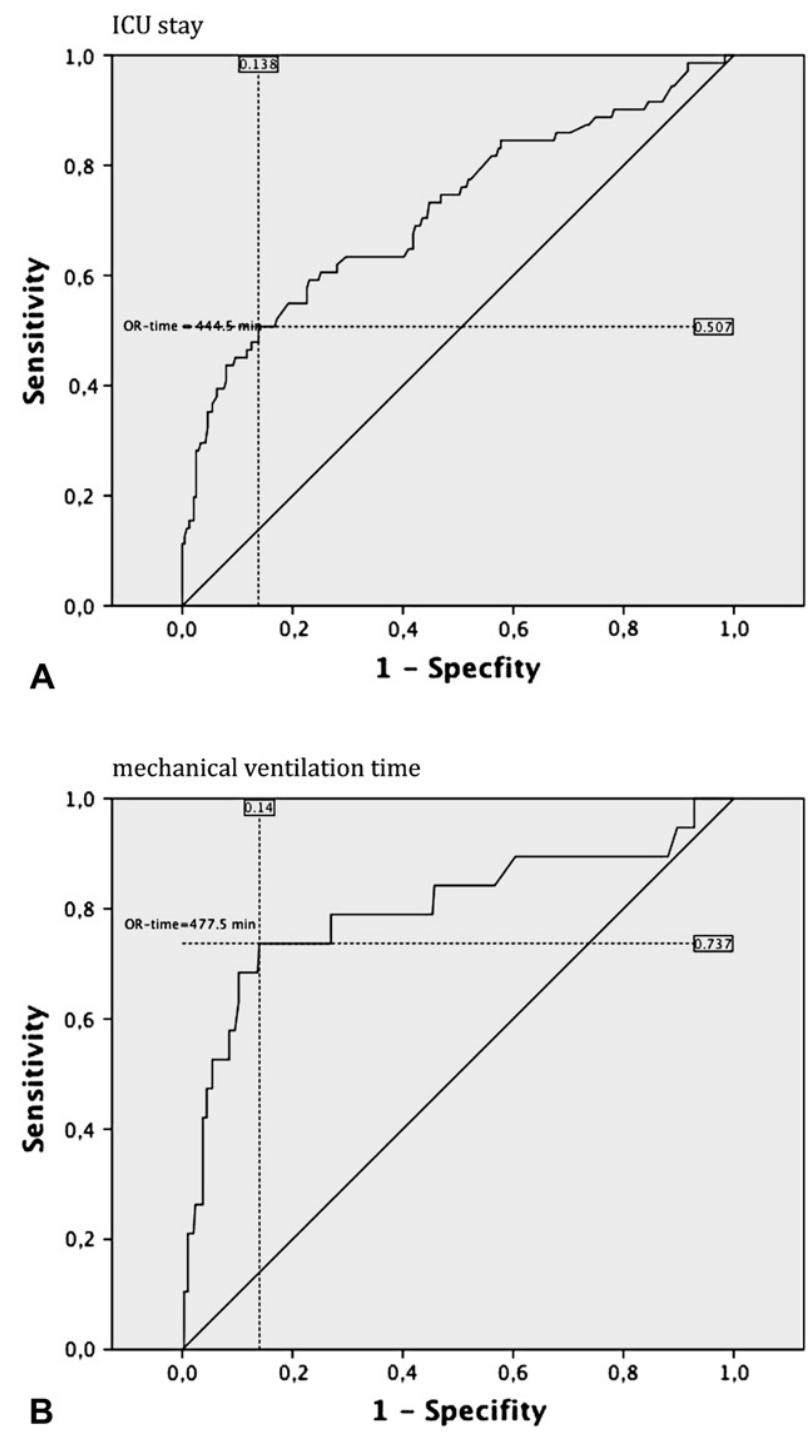

FIGURE 2. A, Receiver operating characteristic analysis for prolonged intensive care unit (ICU) stay. Operative $(O R)$ times of 445 minutes go along with significantly longer times in the intensive care unit. B, Receiver operating characteristic analysis for prolonged mechanical ventilation time. After a cutoff level of 478 minutes, longer operative $(O R)$ time significantly prolongs the postoperative mechanical ventilation time.

problems $(28,22 \%$, vs $26,13 \%, P=.037)$. Forty-five of the 46 conversions were in the group with surgical problems $(P<.001)$.

Regarding the outcome parameters, intensive care unit stay (22 hours; range, 14-389 hours; vs 20 hours; range, 11-1048 hours; $P=.022$ ) and mechanical ventilation time (12 hours; range, 0-288 hours; vs 7 hours; range, $0-349$ hours; $P<.001$ ) were significantly longer in patients with surgical problems The rates of transient ischemic attack, stroke, postoperative renal failure, sepsis, deep sternal wound infection, pneumonia, perioperative myocardial infarction, and in-hospital mortality were not significantly different between the groups. When comparing the survivals of patients with and without surgical problems, we did not see significant differences in Kaplan-Meier survival analysis (Figure E1). Survivals were $98 \%, 98 \%$, and $97 \%$, respectively, in the group without surgical problems at 12,24 , and 36 months after the operation. In the group with surgical problems, survivals were $97 \%, 97 \%$, and $95 \%$, respectively, at 12,24 , and 36 months after surgery $(P=.659)$.

\section{DISCUSSION}

TECAB with the da Vinci surgical telemanipulation system (Intuitive Surgical, Inc, Sunnyvale, Calif) has become a feasible procedure for coronary revascularization at specialized centers. It was the first robotic endoscopic cardiac procedure reported and remains among the most complex robotic surgical operations. Nevertheless, TECAB has been criticized especially because of prolonged operative times relative to open procedures. In this study, we tried to identify predictors of prolonged operative time and analyzed the influence of operative times on the outcome of 325 patients undergoing TECAB.

More complex procedures have been associated with longer operative times. Apart from that, cases with operative problems, especially those ending up in conversions, have also been associated with prolonged operative times. In an early larger series of TECAB procedures, de Cannière and coworkers ${ }^{8}$ described conversion rates of $28 \%$. Even though the conversion rate in our series was significantly lower (14\%), conversion still remained a factor influencing not only operative times but finally also the outcome of patients undergoing TECAB. In our study, it became clear that intraoperative technical challenges impact operative times. Anastomotic problems, left ITA injuries, and epimyocardial lesions were more frequently found in the group of patients with prolonged operative times. It therefore seems to be very important to make all efforts to avoid any surgical problems, and so meticulous attention has to be paid to every detail. This becomes even more obvious when looking at the conversion rates. Whereas patients with operative times shorter than 478 minutes had an acceptable conversion rate of $8 \%$, patients with operative times exceeding 478 minutes had a conversion rate of 4 out of 10 patients. When comparing the results of patients with and without surgical problems, we found that the occurrence of 1 or more surgical problems significantly prolonged the operative time from approximately 5 hours in the group without surgical problems to approximately 7 hours in the group with surgical problems. Nevertheless, this time is still 1 hour below our defined cutoff level of 8 hours. This shows that surgical problems alone prolong the operative time but in most cases it is still possible to stay under the 8-hour limit. When looking at the operative times of complex multivessel revascularizations with bilateral ITA use, 502 minutes on the arrested heart and 504 minutes on the beating heart, it becomes clear that especially multivessel 
TABLE 3. Multivariate analysis for risk factors of prolonged operative time in 325 patients undergoing totally endoscopic coronary artery bypass grafting

\begin{tabular}{lcccc}
\hline \multicolumn{1}{c}{ Variable } & $\boldsymbol{P}$ value & Wald coefficient & Odds ratio & 95\% Confidence interval \\
\hline Bilateral thoracic artery & $<.001$ & 13.512 & 9.674 & $2.885-32.445$ \\
Multivessel totally endoscopic coronary artery bypass grafting & .088 & 2.905 & 2.609 & $0.866-7.859$ \\
Conversion & $<.001$ & 16.980 & 8.897 & $3.146-25.160$ \\
Left internal thoracic artery injury & .335 & 0.652 & 1.874 & $0.522-6.721$ \\
Epimyocardial lesion & .836 & 2.663 & 1.137 & $0.337-3.832$ \\
Anastomotic problems & .103 & 2.663 & 2.742 & $0.816-9.209$ \\
\hline
\end{tabular}

revascularizations in conjunction with surgical problems pose a high risk for extraordinarily long operative times and worse postoperative outcomes. Surgical problems have significant influence on mechanical ventilation time, intensive care unit stay, and hospital stay; however, the rates of postoperative complications were not higher among patients with surgical technical challenges.

Especially during the early period of our TECAB program, we tried to select only low-risk patients, but with a stepwise approach we slowly addressed more complex lesions. Nevertheless, the risk profile of our patients is lower than that of the average patient with coronary artery disease amenable to cardiac surgery. This shows that the TECAB approach is not only attractive for patients and for surgeons performing TECAB but also for referring cardiologists. For low-risk patients, this minimally invasive approach seems

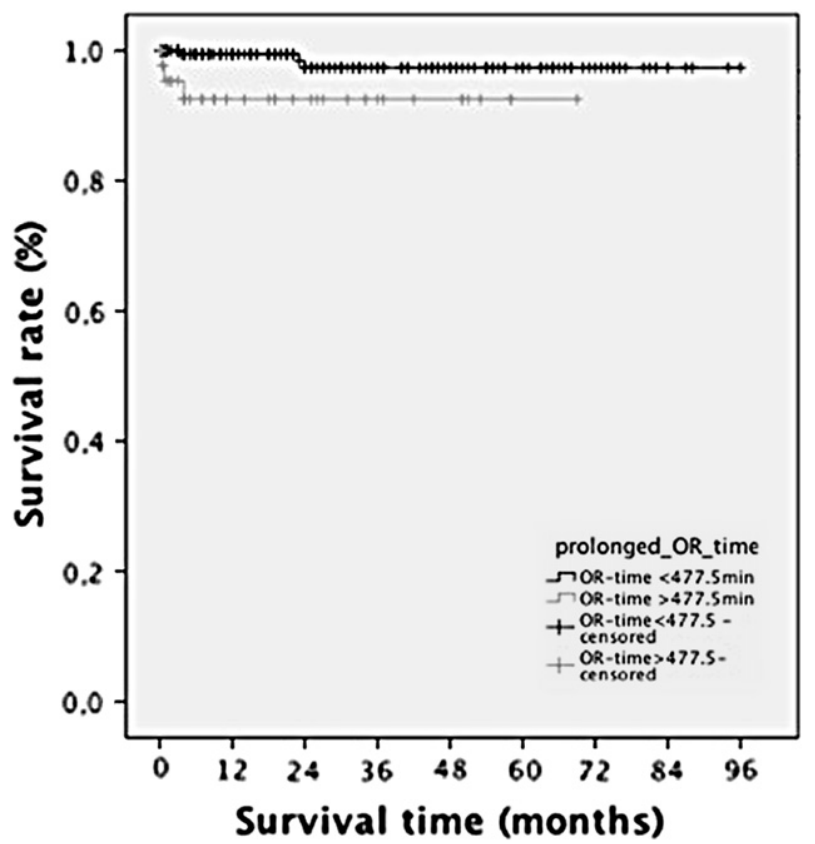

FIGURE 3. Kaplan-Meier survival curves comparing patients with and without prolonged operative $(O R)$ times. Survivals were $99 \%, 98 \%$, and $98 \%$, respectively, in the group without prolonged operative times at 12 , 24 , and 36 months after the operation. In the group with prolonged operative times, survivals were $92 \%, 92 \%$, and $92 \%$, respectively, at 12,24 , and 36 months after surgery $(P=.02)$. Median follow-up was 20 months (range, 0-96 months). to be a more attractive alternative than standard CABG. At our 2 centers, we are currently performing about $20 \%$ of our $\mathrm{CABG}$ procedures with the TECAB technology.

The median operative time of 322 minutes in the overall cohort is longer than the median operative time in standard CABG, although it stays within the limits. Nevertheless procedure times longer than 8 hours should, according to our current analysis, be avoided.

The fact that the operative time among our last 50 patients was the same as that among our first 50 patients (Appendix E1, Table E2) shows that we were able to improve intraoperative performance and to speed up the procedure as the complexity of the procedures (multivessel, beating heart) increased. This shows that it is advisable to start TECAB surgery with simple single left ITA to LAD cases and to address more complex patients only with growing expertise.

There is very little information in the scientific literature about the influence of operative time on the outcomes of patients undergoing conventional or minimally invasive cardiac surgery. Although some studies have shown that minimally invasive approaches can be performed with satisfying outcomes comparable to those of open procedures, ${ }^{9,10}$ at least some of them have shown that the minimally invasive approach is associated with longer operative times than the open approach. Liu and coworkers ${ }^{11}$ compared the outcomes of patients undergoing conventional aortic valve replacement with those of patients undergoing aortic valve replacement with a limited superior sternotomy. The results of these groups were similar, apart from longer operative times in patients undergoing upper hemisternotomy. ${ }^{11}$ Until now, however, no cutoff levels have been found or investigated. Our study shows that TECAB can be performed with satisfying outcomes, especially when staying within certain boundaries regarding the operative time.

The operative times of other minimally invasive CABG strategies are significantly shorter than the operative times of TECAB. For single left ITA to LAD, minimally invasive direct coronary artery bypass approach times as low as 105 minutes have been reported. ${ }^{12}$ Minimally invasive direct coronary artery bypass and multivessel small thoracotomy are attractive approaches for minimally invasive CABG, too, and several groups have report rather promising results with relatively low conversion rates. ${ }^{13}$ Nevertheless, 
TABLE 4. Intraoperative and early postoperative data

\begin{tabular}{|c|c|c|c|c|}
\hline & $\begin{array}{l}\text { All patients } \\
(\mathbf{n}=\mathbf{3 2 5})\end{array}$ & $\begin{array}{c}\text { Operative time } \\
\geq 477.5 \mathrm{~min}(\mathrm{n}=\mathbf{5 6})\end{array}$ & $\begin{array}{c}\text { Operative time } \\
<\mathbf{4 7 7 . 5} \min (\mathrm{n}=\mathbf{2 6 9})\end{array}$ & $P$ value \\
\hline Operative time (min, median and range) & $322(175-724)$ & $552(480-724)$ & $300(175-475)$ & $<.001$ \\
\hline Cardiopulmonary bypass time (min, median and range) & $106(0-444)$ & $196(0-428)$ & $94(0-444)$ & $<.001$ \\
\hline Aortic occlusion time (min, median and range) & $67(0-239)$ & $135(25-231)$ & $63(0-239)$ & $<.001$ \\
\hline Left internal thoracic artery takedown time (min, median and range) & $37(16-85)$ & $40(26-95)$ & $36(4-72)$ & .08 \\
\hline Right internal thoracic artery takedown time (min, median and range) & $35(19-95)$ & $40(26-95)$ & $32(19-72)$ & .03 \\
\hline Anastomotic time, left anterior descending (min, median and range) & $27(10-100)$ & $29(14-100)$ & $26(10-67)$ & .09 \\
\hline Anastomotic time, diagonal branch (min, median and range) & $22(10-50)$ & $25(22-29)$ & $21(10-50)$ & .16 \\
\hline Anastomotic time, marginal branch (min, median and range) & $27(17-70)$ & $29(17-70)$ & $24(17-45)$ & .19 \\
\hline Anastomotic time, right coronary artery (min, median and range) & $27(19-36)$ & $22(19-36)$ & $32(31-32)$ & .36 \\
\hline Beating-heart TECAB (no.) & $54(17 \%)$ & $36(71 \%)$ & $38(14 \%)$ & .023 \\
\hline Multivessel TECAB (no.) & $81(25 \%)$ & $35(69 \%)$ & $46(17 \%)$ & $<.001$ \\
\hline Bilateral thoracic artery use (no.) & $43(13 \%)$ & $27(53 \%)$ & $17(6 \%)$ & $<.001$ \\
\hline Left internal thoracic artery injury (no.) & $19(6 \%)$ & $8(16 \%)$ & $11(4 \%)$ & .003 \\
\hline Anastomotic problem (no.) & $29(9 \%)$ & $10(20 \%)$ & $17(6 \%)$ & $<.001$ \\
\hline Problems with remote access perfusion (no.) & $52(16 \%)$ & $10(20 \%)$ & $39(15 \%)$ & .108 \\
\hline Port problems (no.) & $30(9 \%)$ & $7(14 \%)$ & $23(9 \%)$ & .349 \\
\hline Epimyocardial lesion* (no.) & $26(8 \%)$ & $8(16 \%)$ & $17(6 \%)$ & .047 \\
\hline Hybrid revascularization (no.) & $133(41 \%)$ & $19(37 \%)$ & $111(42 \%)$ & .443 \\
\hline Conversion to larger incision (no.) & $46(14 \%)$ & $21(41 \%)$ & $20(8 \%)$ & $<.001$ \\
\hline Intra-aortic counterpulsation (no.) & $5(1.5 \%)$ & $4(8 \%)$ & $1(0.4 \%)$ & $<.001$ \\
\hline Perioperative myocardial infarction (no.) & $8(2.5 \%)$ & $2(4 \%)$ & $5(2 \%)$ & .126 \\
\hline Intensive care unit stay ( $h$, median and range) & $20(11-1048)$ & $62(14-1048)$ & $20(11-304)$ & $<.001$ \\
\hline Ventilation time ( $\mathrm{h}$, median and range) & $8(0-349)$ & $17(3-349)$ & $8(0-183)$ & $<.001$ \\
\hline Hospital stay (d, median and range) & $6(2-54)$ & $9(5-54)$ & $6(2-35)$ & $<.001$ \\
\hline Packed red blood cells (units, median and range) & $1(0-21)$ & $3(0-21)$ & $1(0-12)$ & $<.001$ \\
\hline Fresh-frozen plasma (units, median and range) & $0(0-31)$ & $0(0-31)$ & $0(0-15)$ & .003 \\
\hline Transient ischemic attack (no.) & $1(0.3 \%)$ & 0 & $1(0.4 \%)$ & 644 \\
\hline Stroke (no.) & $6(2 \%)$ & $2(4 \%)$ & $4(2 \%)$ & .308 \\
\hline Pneumonia (no.) & $10(3 \%)$ & $7(14 \%)$ & $3(1 \%)$ & $<.001$ \\
\hline Postoperative renal failure requiring hemofiltration (no.) & $3(1 \%)$ & $3(6 \%)$ & $0(0 \%)$ & $<.001$ \\
\hline Deep sternal wound infection (after conversion, no.) & $1(0.3 \%)$ & $0(0 \%)$ & $1(0.4 \%)$ & .638 \\
\hline In-hospital mortality (no.) & $2(0.6 \%)$ & $2(4 \%)$ & $0(0 \%)$ & .002 \\
\hline Sepsis (no.) & $1(0.3 \%)$ & $1(2 \%)$ & $0(0 \%)$ & .03 \\
\hline
\end{tabular}

$\overline{T E C A B}$, Totally endoscopic coronary artery bypass grafting. *Epimyocardial lesion was any injury to the epicardium and superficial myocardium that did not result in ventricular rupture but did result in some bleeding and needed to be treated either by suturing or by application of fibrin glue.

minimally invasive direct coronary artery bypass and multivessel small thoractomy also have their shortcomings, ${ }^{14}$ such as difficulties in preparation of the ITA, bad exposure of the target vessels, and the necessity of multiple thoracotomies in case of more complex multivessel revascularizations. Subramanian and colleagues ${ }^{15}$ reported a $3.8 \%$ in-hospital mortality and a $92 \%$ early postoperative graft patency rate in a series of 199 minimally invasive direct coronary artery bypass procedures.

Nobody will doubt that 8 hours and longer represents an extraordinary long operative time for routine CABG cases, but at least most of our procedures could be performed below this limit. Despite the fact that operative times longer than 8 hours for $\mathrm{CABG}$ procedures should not be the goal and should not be accepted without any criticism, our study shows that with a certain safety network, careful patient selection, and meticulous handling, the outcomes of these patients can remain comparable to those undergoing open CABG procedures with shorter operative times even when such long operative times occur. Nevertheless, it has to be a future goal to reduce operative times and to identify patients at high risk for such long operative times. Some of those should probably be excluded from a TECAB procedure.

Overall, we can recommend that operative times of 8 hours and longer should be avoided. One should be rather proactive toward a conversion when the 8-hour limit is about to be exceeded. Nevertheless, we should not recommend conversion for every patient with prolonged operative time. Individual decisions are necessary. When operative problems occur and the operative time is already about to exceed the 8-hour limit, from our point of view an immediate conversion should be the consequence. If only the patient setup or the harvesting and preparation of the ITAs lasts long, and the remainder of the procedure can most 
likely be performed without any further problems, longer operative times can probably be tolerated.

Mihaljevic and associates ${ }^{16}$ recently reported on results of robotic mitral valve repair in comparison with open approaches and minithoracotomy approaches. The robotic approach required an increased operative time but resulted in a reduced hospital stay. The operative time in that series, however, was in the 6-hour range, and complex mitral valve repair was not included. In addition, a low-risk patient cohort was treated.

The perioperative results in our whole series of robotic TECAB and results in patients who were operated within the 8-hour time limit were very acceptable. Perioperative mortality was clearly lower than predicted by EuroSCORE. Morbidity in patients with prolonged operative time primarily included respiratory issues and a prolonged ventilation time. Single-lung ventilation, which is a necessary measure in TECAB, has probably contributed to respiratory problems; additionally, an increased number of blood transfusions and prolonged cardiopulmonary bypass times may have been causal factors. A higher incidence of renal failure after prolonged surgery can be explained by extended times on heart-lung machine support, by longer times of singlelung ventilation and continuous thoracic carbon dioxide inflation, and by lower systemic perfusion pressures in cases of significant surgical bleeding. Increased rates of pneumonia and sepsis in patients with extensive operative times may be due to a depressed state of the immune system and a prolonged application of invasive measures in the operating room and the intensive care unit.

There was a $6 \%$ lower survival at 3 years among patients with significantly prolonged operative times, and most deaths occurred during the first 6 postoperative months. The fact that there was no significant difference in survival between patients with and without surgical problems shows that surgical problems alone, even though they are an important factor, are not the only causal factors of adverse postoperative outcome for patients undergoing TECAB. Other factors, such as the complexity of the procedure, may also have a significant impact not only on operative time but also on postoperative outcome.

Our results clearly show that the overall survival of patients undergoing TECAB is within the range of conventional CABG, and the 99\% 1-year survival and 98\% 3-year survival among patients with operative times below the cutoff value can both be regarded as exceptionally good. It has to be pointed out that only 6 patients in the whole series of 325 TECAB procedures died perioperatively or during the follow-up period. In the group with operative times shorter than 478 minutes, there were no in-hospital deaths, and 1 of the 3 patients who died in the long-term follow-up actually died of prostate cancer. In the group with prolonged operative times, 1 of the 2 in-hospital deaths was due to intracerebral bleeding. In the long-term follow-up, 1 other patient in that group died of cardiac causes. This means that means that only 4 of the 6 deaths in our series were cardiac related.

The possible beneficial effects of TECAB, such as smaller incisions, preservation of the integrity of the chest wall, better cosmesis, shorter hospital stay, and quality of life improvement, overcome such disadvantages as longer operative times and higher costs and resource use. Nevertheless, we are aware that TECAB remains an approach for a selected group of patients and will probably be performed only in dedicated centers.

Our results indicate that operative time is an issue and that measures that can dampen learning curves and speed up the operative time are mandatory. We conclude that multivessel revascularization, operations on the beating heart, and technical difficulties can lead to prolonged operative times in robotic TECAB. Operative times as long as 8 hours seem to be tolerable and are associated with excellent perioperative and long-term outcomes, whereas procedures exceeding the 8-hour time frame may be associated with increased perioperative morbidity and mortality, as well as decreased long-term survival. Complex multivessel procedures should receive special surgical attention.

\section{References}

1. Loulmet D, Carpentier A, d'Attellis N, Berrebi A, Cardon C, Ponzio O, et al. Endoscopic coronary artery bypass grafting with the aid of robotic assisted instruments. J Thorac Cardiovasc Surg. 1999;118:4-10.

2. Bonatti J, Schachner T, Bonaros N, Oehlinger A, Danzmayr M, Rützler E, et al. Ongoing procedure development in robotically assisted totally endoscopic coronary artery bypass grafting (TECAB). Heart Surg Forum. 2005; 8:E287-91

3. Bonatti J, Schachner T, Bonaros N, Oehlinger A, Wiedemann D, Ruetzler E, et al. Effectiveness and safety of total endoscopic left internal mammary artery bypass graft to the left anterior descending artery. Am J Cardiol. 2009;104:1684-8.

4. Bonaros N, Schachner T, Wiedemann D, Oehlinger A, Ruetzler E, Feuchtner G, et al. Quality of life improvement after robotically assisted coronary artery bypass grafting. Cardiology. 2009;114:59-66.

5. Schachner T, Bonaros N, Wiedemann D, Weidinger F, Feuchtner G, Friedrich G, et al. Training surgeons to perform robotically assisted totally endoscopic coronary surgery. Ann Thorac Surg. 2009;88:523-7.

6. Wiedemann D, Bonaros N, Schachner T, Schwaiger C, Biebl M, Friedrich G, et al. Single-lung ventilation time does not increase lung injury after totally endoscopic coronary artery bypass surgery. Heart Surg Forum. 2010;13: E383-90.

7. Bonatti J, Schachner T, Bonaros N, Ohlinger A, Danzmayr M, Jonetzko P, et al. Technical challenges in totally endoscopic robotic coronary artery bypass grafting. J Thorac Cardiovasc Surg. 2006;131:146-53.

8. de Cannière D, Wimmer-Greinecker G, Cichon R, Gulielmos V, Van Praet F, Seshadri-Kreaden U, et al. Feasibility, safety, and efficacy of totally endoscopic coronary artery bypass grafting: multicenter European experience. J Thorac Cardiovasc Surg. 2007;134:710-6.

9. Mihaljevic T, Cohn LH, Unic D, Aranki SF, Couper GS, Byrne JG. One thousand minimally invasive valve operations: early and late results. Ann Surg. 2004;240: 529-34.

10. Tabata M, Umakanthan R, Cohn LH, Bolman RM 3rd, Shekar PS, Chen FY, et al. Early and late outcomes of 1000 minimally invasive aortic valve operations. Eur J Cardiothorac Surg. 2008;33:537-41.

11. Liu J, Sidiropoulos A, Konertz W. Minimally invasive aortic valve replacement (AVR) compared to standard AVR. Eur J Cardiothorac Surg. 1999;16(Suppl. 2): S80-3.

12. Fraund S, Behnke H, Boening A, Cremer J. Immediate postoperative extubation after minimally invasive direct coronary artery surgery (MIDCAB). Interact Cardiovasc Thorac Surg. 2002;1:41-5. 
13. Al-Ruzzeh S, Mazrani W, Wray J, Modine T, Nakamura K, George S, et al. The clinical outcome and quality of life following minimally invasive direct coronary artery bypass surgery. J Card Surg. 2004;19:12-6.

14. Weigang E, Royl J, Dencker A, Schoellhorn J, van de Loo A, Beyersdorf F. Results after MIDCAB and OPCAB surgeries: problems and consequences of incomplete angiographic follow-up in the mid-term course. Interact Cardiovasc Thorac Surg. 2004;3:302-8.
15. Subramanian VA, McCabe JC, Geller CM. Minimally invasive direct coronary artery bypass grafting: two-year clinical experience. Ann Thorac Surg. 1997; 64:1648-55.

16. Mihaljevic T, Jarrett CM, Gillinov AM, Williams SJ, DeVilliers PA, Stewart WJ, et al. Robotic repair of posterior mitral valve prolapse versus conventional approaches: potential realized. J Thorac Cardiovasc Surg. 2011 141:72-80.e1-4.

Access to The Journal of Thoracic and Cardiovascular Surgery Online is reserved for print subscribers!

Full-text access to The Journal of Thoracic and Cardiovascular Surgery Online is available for all print subscribers. To activate your individual online subscription, please visit The Journal of Thoracic and Cardiovascular Surgery Online, point your browser to http://www.mosby.com/itcvs, follow the prompts to activate your online access, and follow the instructions. To activate your account, you will need your subscriber account number, which you can find on your mailing label (note: the number of digits in your subscriber account number varies from 6 to 10). See the example below in which the subscriber account number has been circled:

\section{Sample mailing label}

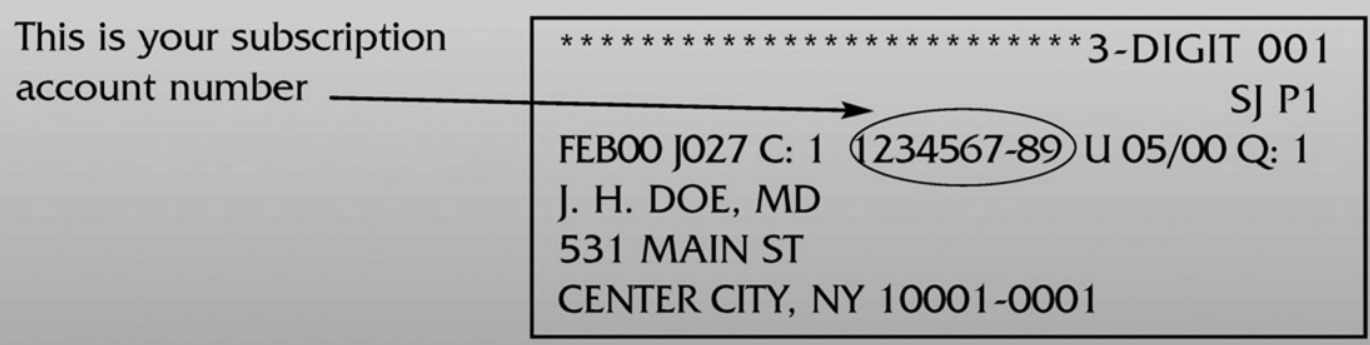

Personal subscriptions to The Journal of Thoracic and Cardiovascular Surgery Online are for individual use only and may not be transferred. Use of The Journal of Thoracic and Cardiovascular Surgery Online is subject to agreement to the terms and conditions as indicated online. 


\section{APPENDIX E1. RESULTS OF THE FIRST 50 PATIENTS TO UNDERGO TOTALLY ENDOSCOPIC CORONARY ARTERY BYPASS GRAFTING IN COMPARISON TO THE LAST 50 PATIENTS}

Another important issue regarding operative times and operative problems is the development of the totally endoscopic coronary artery bypass grafting program and the increasing expertise of the surgeons with the growing case number. We analyzed the results and the characteristics of the first and last 50 patients undergoing totally endoscopic coronary artery bypass grafting within our program (Table E2). With time, we tackled more complex lesions. There were significantly more multivessel revascularizations $(\mathrm{n}=6,12 \%$, vs $\mathrm{n}=16,31 \%)$, bilateral internal thoracic artery use $(\mathrm{n}=2,4 \%$, vs $\mathrm{n}=11,22 \%)$, and beating-heart procedures $(\mathrm{n}=8,16 \%$, vs $\mathrm{n}=20,39 \%)$ among the last 50 patients than among the first 50 . Both operative time (365 minutes; range, 243-724 minutes; vs

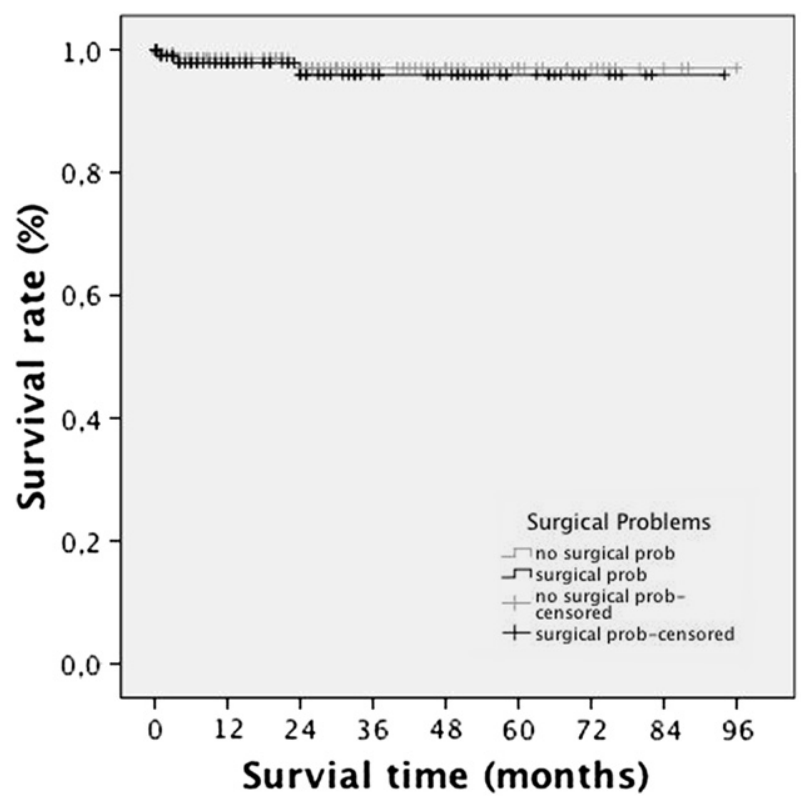

FIGURE E1. Kaplan-Meier survival curves comparing patients with and without surgical problems (prob). Survivals were $98 \%, 98 \%$, and $97 \%$, respectively, in the group without surgical problems at 12, 24, and 36 months after the operation. In the group with surgical problems, survivals were $97 \%, 97 \%$, and $95 \%$, respectively, at 12,24 , and 36 months after surgery ( $P=.659$ ). Median follow-up was 20 months (range, 0-96 months).
335 minutes; range, 194-692 minutes) and aortic occlusion time (77 minutes; range, 0-223 minutes; vs 71 minutes; range, 0-147 minutes) were not significantly different, whereas the cardiopulmonary bypass time was significantly longer in the group of the first 50 patients (120 minutes; range, 0-368 minutes; vs 96 minutes; range, 0-348 minutes). There were 10 conversions among the first 50 patients $(20 \%)$ and $5(10 \%)$ among the last 50 patients $(P=.14)$, and surgical problems occurred in 26 of the first 50 patients $(52 \%)$ and in 16 of the last 50 patients $(31 \%$, $P=.08)$. The were no differences in rates of transient ischemic attack, stroke, pneumonia, sepsis, deep sternal wound infection, renal failure, postoperative myocardial infarction, and in-hospital mortality (no in-hospital deaths among the first 50 patients vs 2 in-hospital deaths [4\%] among the last 50 patients, $P=.247$ ). Intensive care unit stay, mechanical ventilation time, and hospital stay were equivalent between the groups. 
TABLE E1. Clinical data of patients with and without surgical problems

\begin{tabular}{|c|c|c|c|}
\hline & $\begin{array}{l}\text { Surgical problems } \\
(\mathrm{n}=\mathbf{1 2 0}, \mathbf{3 7} \%)\end{array}$ & $\begin{array}{l}\text { No surgical problems } \\
\quad(n=205,63 \%)\end{array}$ & $P$ value \\
\hline Operative time ( $\mathrm{min}$, median and range) & $418(245-724)$ & $293(175-656)$ & $<.001$ \\
\hline Cardiopulmonary bypass time (min, median and range) & $139(0-444)$ & $92(0-270)$ & $<.001$ \\
\hline Crossclamp time (min, median and range) & $86(0-239)$ & $63(0-153)$ & $<.001$ \\
\hline EuroSCORE (median and range) & $2(0-7)$ & $1.5(0-8)$ & .181 \\
\hline Intensive care unit stay ( $h$, median and range) & $22(14-389)$ & $20(11-1048)$ & .022 \\
\hline Mechanical ventilation time ( $h$, median and range) & $12(0-288)$ & $7(0-349)$ & $<.001$ \\
\hline Hospital stay (d, median and range) & $7(2-23)$ & $6(3-54)$ & .065 \\
\hline Packed red blood cells (units, median and range) & $2(0-21)$ & $0(0-8)$ & $<.001$ \\
\hline Multivessel TECAB (no.) & $36(29 \%)$ & $45(23 \%)$ & .18 \\
\hline Beating-heart TECAB (no.) & $28(22 \%)$ & $26(13 \%)$ & .037 \\
\hline Bilateral internal thoracic artery use (no.) & $19(16 \%)$ & $22(12 \%)$ & .3 \\
\hline Conversion (no.) & $45(36 \%)$ & $1(0.5 \%)$ & $<.001$ \\
\hline Transient ischemic attack (no.) & $1(0.8 \%)$ & 0 & .39 \\
\hline Stroke (no.) & $4(3 \%)$ & $4(2 \%)$ & .68 \\
\hline Renal failure requiring hemofiltration (no.) & $2(1.7 \%)$ & 0 & .15 \\
\hline Sepsis (no.) & $1(0.8 \%)$ & 0 & .39 \\
\hline Deep sternal wound healing problems (after conversion, no.) & $1(0.8 \%)$ & 0 & .39 \\
\hline In-hospital mortality (no.) & $2(2 \%)$ & $2(1 \%)$ & .63 \\
\hline Perioperative myocardial infarction (no.) & $5(4.2 \%)$ & $2(1 \%)$ & .12 \\
\hline Intra-aortic counterpulsation pump (no.) & $3(2.5 \%)$ & $1(0.5 \%)$ & .3 \\
\hline Pneumonia (no.) & $5(4 \%)$ & $5(3 \%)$ & .6 \\
\hline
\end{tabular}

$T E C A B$, Totally endoscopic coronary artery bypass grafting.

TABLE E2. Program development

\begin{tabular}{|c|c|c|c|}
\hline & First 50 & Last 50 & $P$ value \\
\hline Male (no.) & $37(74 \%)$ & $39(77 \%)$ & .5 \\
\hline Age (y, median and range) & $59(42-74)$ & $59(42-77)$ & .626 \\
\hline EuroSCORE (median and range) & $1(0-4)$ & $2(0-8)$ & .008 \\
\hline Beating-heart TECAB & $8(16 \%)$ & $20(39 \%)$ & .013 \\
\hline Multivessel TECAB & $6(12 \%)$ & $16(31 \%)$ & .028 \\
\hline Bilateral internal thoracic artery use (no.) & $2(4 \%)$ & $11(22 \%)$ & .015 \\
\hline Conversion (no.) & $10(20 \%)$ & $5(10 \%)$ & .14 \\
\hline Surgical problems (no.) & $26(52 \%)$ & $16(31 \%)$ & .08 \\
\hline Perioperative myocardial infarction (no.) & $3(6 \%)$ & 0 & .243 \\
\hline Intra-aortic counterpulsation pump (no.) & $1(2 \%)$ & 0 & .521 \\
\hline Transient ischemic attack (no.) & 0 & 0 & NA \\
\hline Stroke (no.) & 0 & $1(2 \%)$ & .222 \\
\hline Pneumonia (no.) & $3(6 \%)$ & $1(2 \%)$ & .540 \\
\hline Sepsis (no.) & $1(2 \%)$ & 0 & .521 \\
\hline Deep sternal wound infection (no.) & 0 & $1(2 \%)$ & .479 \\
\hline In-hospital mortality (no.) & 0 & $2(4 \%)$ & .247 \\
\hline Operative time (min, median and range) & $365(243-724)$ & $335(194-692)$ & .237 \\
\hline Cardiopulmonary bypass time (min, median and range) & $120(0-368)$ & $96(0-348)$ & .033 \\
\hline Aortic crossclamp time (min, median and range) & $77(0-223)$ & $71(0-147)$ & .471 \\
\hline Intensive care unit stay ( $\mathrm{h}$, median and range) & $24(11-389)$ & $25(13-384)$ & .994 \\
\hline Hospital stay (d, median and range) & $7(2-22)$ & $7(3-35)$ & 690 \\
\hline Packed red blood cells (units, median and range) & $2(0-21)$ & $2(0-7)$ & .635 \\
\hline Renal failure requiring hemofiltration (no.) & 0 & 0 & NA \\
\hline
\end{tabular}

TECAB, Totally endoscopic coronary artery bypass grafting; $N A$, not applicable. 